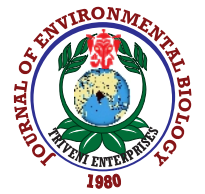

\title{
Bactericidal effect of Neem (Azadirachta indica) leaf extract on Helicobacter pylori
}

\author{
A. Saxena', P. Arivaradarajan', A.K. Mukhopadhyay ${ }^{2}$ and S.P. Nandi ${ }^{3 *}$ \\ ${ }^{1}$ Amity Institute of Biotechnology, Amity University, Noida-201 313, India \\ ${ }^{2}$ Bacteriology Division, ICMR-National Institute of Cholera and Enteric Diseases, Kolkata-700 010, India \\ ${ }^{3}$ Centre for Cellular and Molecular Biotechnology, Amity Institute of Biotechnology, Amity University, Noida-201 313, India \\ *Corresponding Author Email : spaul@amity.edu
}

\section{Abstract}

Aim: The aim of the present study was to investigate the antibacterial effect of ethanolic extract of neem (Azadirachta indica) leaf against Gram-negative, gastric pathogen, Helicobacter pylori (H. pylori).

Methodology: Extracts of neem leaf were prepared in different solventslike hexane, dichloromethane, chloroform, ethyl acetate, acetone and ethanol. Antibacterial activity was estimated in terms of zone of inhibition by performing Agar cup diffusion assay. Depending on the diameter of zone of inhibition, ethyl acetate, acetone and ethanol extract of neem leaves were selected for Thin Layer Chromatography. The presence of photochemicals were detected using iodine fumigation. Elution Assay was done to detect the bioactive components of the ethanol extract.

Results: Out of sixsolvents used, ethanol extract of neem leavesshowed the maximum zone of inhibition against $H$. pylori. TLC separation of ethyl acetate, acetone and ethanol extract of plant products showed dark brown bands of phytochemicals on silica-gel $\mathrm{G} 60$ plates. The contact bioautography assay showed a zone of $15 \mathrm{~mm}$. Elution assay and agar cup bioassay was performed against $H$. pylori and the loading spot showed a zone of $11 \mathrm{~mm}$.

Interpretation: The findings of the present study revealed the antibacterial potency of ethanolic extracts of neem (Azadirachta indica) leaf against Gram-negative gastric pathogen H. pylori. The ethanolic extract of neem leaf can be used as an effective natural remedy in combating $H$. pylori infection.

Key words: Agar cup diffusion assay, Azadirachta indica, Helicobacter pylori, Phytochemicals

How to cite : Saxena, A., P. Arivaradarajan, A.K. Mukhopadhyay and S.P. Nandi: Bactericidal effect of neem (Azadirachta indica) leaf extract on Helicobacter pylori. J. Environ. Biol., 42, 1591-1597 (2021).
Neem (Azadirachta indica) leaf extracts prepared in different solvents

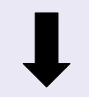

Determination of Zone of inhibition ( $\mathrm{mm}$ ) of neem leaf (Azadirachta indica) extract against Helicobacter pylori using Agar-cup diffusion assay

Thin layer chromatography of ethyl acetate, acetone and ethanol extracts $(50 \mu \mathrm{l})$ of Neem (Azadirachta indica) leaf

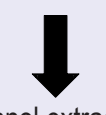

Thin layer chromatography of ethanol extracts $(50 \mu \mathrm{l})$ of neem (Azadirachta indica) leaf using contact bioautography, followed by Elution assay

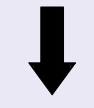

Study revealed anti-bacterial activity of ethanolic extracts of neem (Azadirachta indica) leaf against Gram-negative gastric pathogen Helicobacter pylori. 


\section{Introduction}

Helicobacter pylori (H. pylori) is a Gram-negativebacteria that causes infection in the stomach. They have a distinctive characteristic to prosper and survive in highly acidic environments of the stomach (Warren and Marshall, 1983). The precise cause of $H$. pylori spread among the population is not known. Nevertheless, it is believed that the fecal-oral or oral-oral route due to consumption of contaminated water or food is a common cause (Brown, 2000; Stefano et al., 2018). The spread of $H$. pylori is almost $50 \%$ throughout the world and the infection is linked with the development of ulcers, gastric cancer, and mucosa-associated lymphoid tissue (MALT) lymphoma (Burkitt et al., 2017; Hooi et al., 2017). The alarmingly high spread of antibiotic-resistant $H$. pylori is increasing extensively throughout the world (Thung et al., 2016). The World Health Organization in 2017 has listed $H$. pylori as priority-2 antibiotic resistant pathogen for which research and development of new antibiotics is crucial. In addition to this, the recurrence of $H$. pylori infection cannot be neglected. $H$. pylori infection has an ability to persist for the entire life, if not eradicated from the system. The conventional triple therapy with 2 antibiotics and a proton pump inhibitor has been used for almost 20 years to combat $H$. pylori infection, but there is low treatment success, which is unacceptable when it comes to grading the H. pylori treatment (Graham and Fishbach, 2010).

The mechanism of $H$. pylori infection among the population is not known, however, the bacterium has the ability to chronically colonize the human gastric mucosa. International Agency for Research on Cancer, 2012 has classified the bacterium $H$. pylori as a carcinogen. In this scenario, herbal therapy appears to be a promising alternative to address $\mathrm{H}$. pyloriinfection (Saxena et al., 2020a). One of the endogenous plants of Maliaceae family in Indian subcontinent is neem (Azadirachta Indica) that grows well even in adverse environmental conditions. The neem has been used in folk medicine for thousands of years. The active ingredient of neem is azadirachtin, a limonoid. This medicinal plantparts has been used in India for multiple biological activities (Nadkarni, 1954; National Research Council, 1992). Extracts and purified compounds from neem trees possess largely antibacterial activity (Al Akeel et al., 2017; Al Saiqali et al., 2018; Thakurta et al., 2007). Additionally, the neem plant extracts have also been reported to possess antifungal (Fabry et al., 1996b), antiparasitic (Dahiya et al., 2016), and antiviral (Parida et al., 2002) activities. Neem has been stated to have more than 300 bioactive isolates (Gupta et al., 2017).

Many commercial biological pesticides also contain azadirachtin from the liminoid of neem tree. Use of natural products from medicinal plants for new therapeutics has grown many folds over the last four decades resulting in the approval of many small-molecule antibacterial agents world-over (Newman and Cragg, 2016). Looking at the sensitivity of neem tree components against bacteria, the World Health Organization (WHO) (2017) has shown great concern for the need of developing new antibiotics for pathogens like Campylobacter jejuni, Klebsiella pneumoniae, Pseudomonas aeruginosa, Escherichia coli, Salmonella enterica, and Staphylococcus aureus. Neem extract has several favorable pharmacological properties, including the ability to kill non-growing bacteria, increased activity at low $\mathrm{pH}$, and no hemolytic activity. The upcoming treatment for $\mathrm{H}$. pylori infection could be the compound (s) present in the Nee mextract (Blum et al., 2018). With this background for developing novel therapeutics, the present study was carried out to investigate the antibacterial effect of ethanolic extract of neem (Azadirachta indica) leaf against Gram-negative, gastric pathogen, Helicobacter pylori (H. pylori).

\section{Materials and Methods}

Plant collection: Fresh leaves of $A$. indica leaves were collected from the University of Agriculture and Technology, Ayodhya. The leaves of $A$. indica were washedwith water, driedat ambient temperature, and regularly examined to check for any fungal growth. The voucher specimen was deposited in the New Drugs and Innovation Laboratory, Amity Institute of Biotechnology, Amity University Uttar Pradesh, India for future reference.

Culture and maintenance of bacterial strains: $H$. pyloribacterial strain 26695 (ATCC 700392) was procured from the Bacteriology Division, National Institute of Cholera and Enteric Diseases (NICED) Kolkata, India. H. pylori were grown in Brain Heart Infusion (BHI) media in microaerophilic environment $\left(5 \% \mathrm{O}_{2}, 10 \% \mathrm{CO}_{2}\right.$ and $\left.85 \% \mathrm{~N}_{2}\right)$ at $37^{\circ} \mathrm{C}$ temperature and $60-70 \%$ humidity.

Preparation of plant extract: Dried and finely crushed $A$. indica leaves were soaked in hexane in a sterile conical flask. The flask was kept at $37^{\circ} \mathrm{C}$ in the incubator-shaker for $24 \mathrm{hr}$. The content from the flask was filtered through Whatman No. 1filter paper, and the residue was re-soaked in dichloromethane fornext $24 \mathrm{hrs}$, followed by chloroform, ethyl acetate, acetone, and ethanol. Filtrates were concentrated to dryness. Weighed and dissolved in same solvents, and filtrate was finally stored in a sterile glass vial at $4^{\circ} \mathrm{C}$.

Antibacterial screening: Modified agar well diffusion method was used for initial screening of plant extracts against the pathogenic strain (Perez et al., 1990). Standardized inoculum $(100 \mu \mathrm{l})$ of $0.5 \mathrm{McF}$ arland turbidity equivalent to $5 \times 10^{8} \mathrm{cfuml}^{-1}$ of test strain (Helicobacter pylori) was spread using a sterile glass spreader onto sterile BHlagar plates to achieve auniform growth. With the help of a sterile cork borer ( $8.0 \mathrm{~mm}$ diameter), wells were prepared in the $\mathrm{BHI}$ plates. The extracts $50 \mu \mathrm{l}\left(65 \mu \mathrm{g} \mu \mathrm{l}^{-1}\right)$ were loaded into the wells and $70 \%$ of respective solvents ( $50 \mu \mathrm{l} /$ well) were taken as a negative control. The plates were then incubated at $37^{\circ} \mathrm{C}$ for $48 \mathrm{hr}$ in a gas jar with microaerophilic conditions $(5 \%$ $\mathrm{O}_{2}, 10 \% \mathrm{CO}_{2}$ and $85 \% \mathrm{~N}_{2}$ ). The diameter of the zone of inhibition was measured in millimeters to access the anti-helicobacter pyloric activity. The experiment was done thrice and the mean values were calculated.

Chemical characterization: The ethanol extracts of $A$. indica 
leaves that showed growth inhibition were loaded on a TLC plate pre-coated with silica gel $60 \mathrm{~F}_{254}$ sheets (Merck, Darmstadt, Germany).

Chemical characterization of bioactive TLC spots: The loaded TLC sheets were run in solvent mixture Toulene: Chloroform: Acetone (40:25:35). Oncethe run was complete, TLC sheets were air dried and then subjected to iodine fumigation. The bioactive spots could be seen clearly after iodine fumigation.

Separation of compounds by TLC and identification of bioactive spots by contact bioautography: Fifty microliter of plant extract was spotted on pre-coated silica gel. One dimensional TLC was performed using solvent mixture T:C:A (40:25:35). After drying, for contact bioautography, the chromatogram was placed face down onto $H$. pylori inoculated $\mathrm{BHI}$ agar plate to enable diffusion and the plate was incubated at $37^{\circ} \mathrm{C}$ for $48 \mathrm{hrs}$ under microaerophilic conditions in the presence of high humidity (60-70\%). The bioactive spots were identified by zone of $H$. pylorigrowth inhibition.

Elution Assay: The bioactive spots from TLC (run with ethanol extract of $A$. indica) were scraped and resuspended in ethanol. The vials were kept on a rocker-shaker for $2 \mathrm{hr}$. Thereafter, the vials were centrifuged at $5,000 \mathrm{rpm}$ for $10 \mathrm{~min}$ at room temperature and the supernatant was separated followed by air drying. Once the volume of bioactive spots reached $50 \mu \mathrm{l}$, the vials were sealed to prevent further evaporation. Fifty microliter of each eluted bioactive spot was tested for anti-helicobacter pyloric activity as per the antibacterial screening described above.

Statistical Analysis: Data were means of inhibition zones of antibacterial activity of leaf extract. The experiments were been repeated three times and the results were analyzed using Student's t- test.

\section{Results and Discussion}

Medicinal plants having therapeutic properties have been recognized as folk medicinein many countries. Previously several authors have exhibited inhibitory activity of some plant extracts against H. pylori (Moghaddam, 2011; Malekzadeh et al., 2001; Cellini et al., 1996). The medicinal plant, neem has been known for many therapeutics implications. Alzohairy (2016) reported several biological and pharmacological activities that include antibacterial, antifungal and anti-inflammatory, as well as antipyretic, anti-gastric ulcer, anti-arthritic, hypoglycemic, and antitumor activities. Additionally, the study summarized the role of neem and its active ingredients in disease prevention and treatment by modulation of various biological pathways. In the present study agar cup bioassay had shown zone of inhibition $(12-18 \mathrm{~mm})$ against $H$. pylori in extracts of neem leaf prepared in ethanol, acetone, chloroform and ethyl acetate but failed to show zone of inhibition in hexane and DCM extracts (Fig. 1).

In the qualitative assessment, smaller zone of inhibition revealed resistant bacteria whereas larger zone of inhibition indicated susceptible bacteria. These findingsare indicative of the

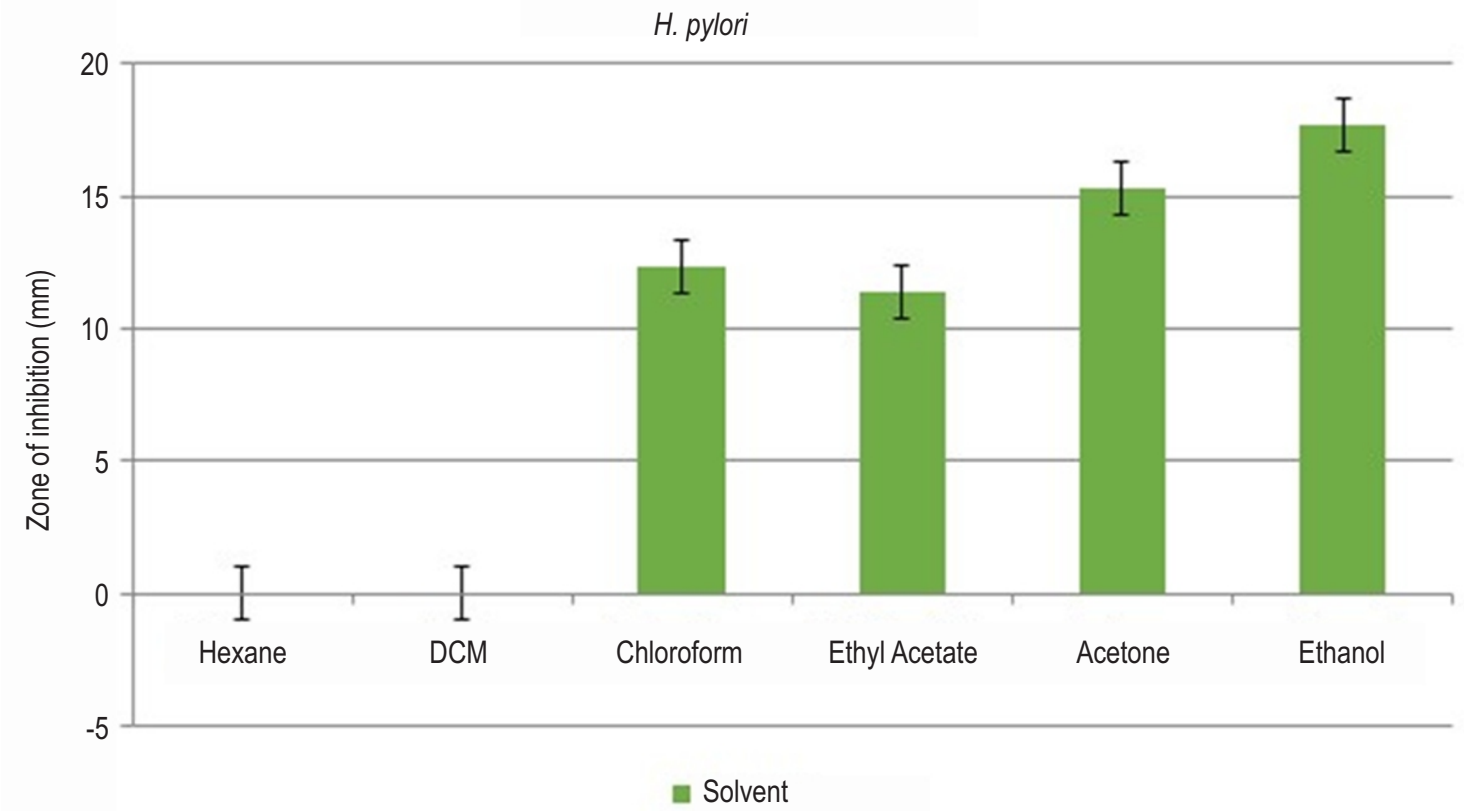

Fig. 1: Zone of Helicobacter pylorigrowth inhibition of Neem (Azadirachta indica) leaf extracts using Agar cup assay. 


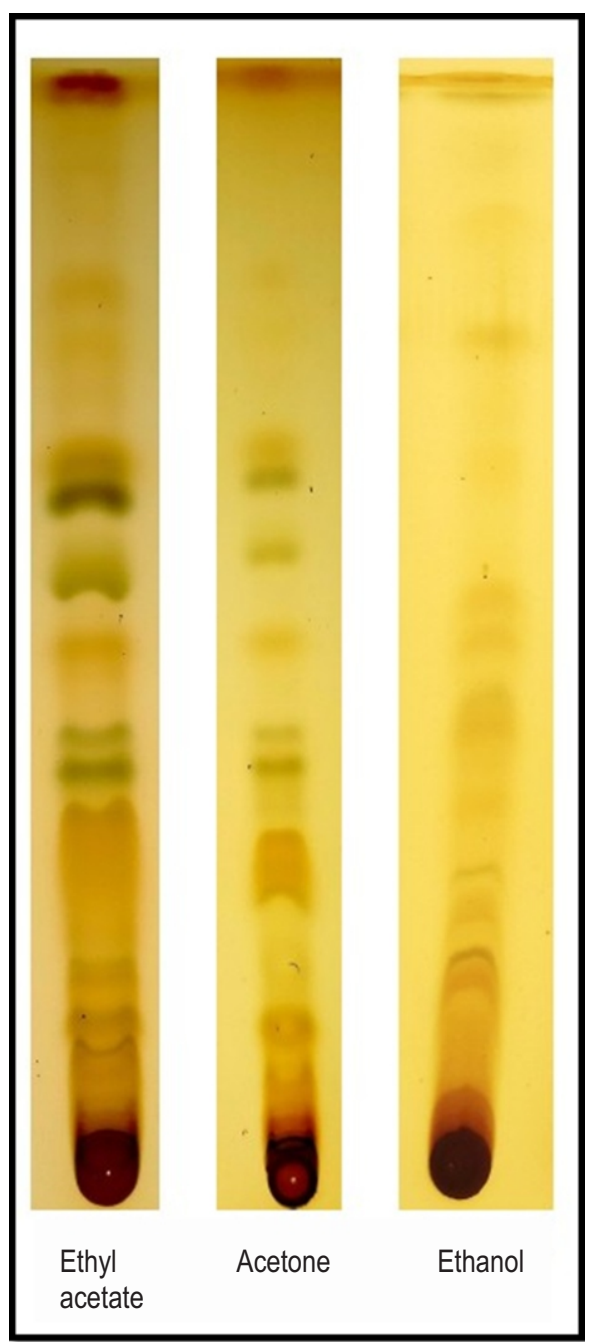

Fig. 2: Thin Layer Chromatography, loaded with $50 \mu$ l of ethyl acetate, acetone and ethanol extract of neem (Azadirachta indica) leaf showing movement of the bands of bioactive compounds.

bactericidal activity of neem leaves, projecting it as a suitable and effective plant for fighting Gram-negative gastric pathogen, $H$. pylori infection. Saxena et al. (2020b) reported the antibacterial activity of $E$. officinalis (fruit), $S$. aromaticum (bud), $R$. indica (petals) and A.indica (leaf) against some Gram-positive and Gram-negative pathogenic bacteria. Contrary to this, Fabry et al. (1996a, b; 1998) hadreported that neem leaf extracts did not show antibacterial activity against Klebsiella spp., $S$. aureus, $P$. aeruginosa, Enterococcis pp., E. coli, Salmonella spp., and some Candida spp, but stem bark extract of neem had significant antibacterial activity. Saradhajyothi and Subbarao (2011) also reported the antibacterial effect of Azadirachta indica leaf extract against Escherichia coli, Klebsiella pneumonia, Proteus vulgaris Micrococcusluteus, Bacillus subtilis, Enterococcus faecalis and Streptococcus faecalis. Kumar et al. (2013) had reviewed the basic principles and the significance of TLC technique in research in general and phyto-chemistry in specific. TLC technique is regularly applied to separate chemical and biochemical compounds. In the present study, the pre-coated TLC (Fig. 2) showed movement of the bands indicating the presence of bioactivity against $H$. pylori, which was further confirmed by contact bioautography. Methanolic leaves extracts of plant Eucalyptus camaldulensis and Terminalia catappahad shown inhibitory effects on the microorganisms. Authors have identified the presence of the phytochemical components in the extract (Babayi et al., 2004). Similar to the present study, Mehrotra et al. (2010) has reported the antimicrobial activity of ethanol extract of neem leaves against $S$. aureus and $V$. cholera. Authors have identified bioactive components in extract effective against multiple pathogens. The antibacterial activity observed with agar cup diffusion study was confirmed by contact bioautography.

A zone of inhibition of $16 \mathrm{~mm}$ was observed with contact bioautography of ethanol extract of neem leaves kept face down onantibiotic resistant pathogen; $\mathrm{H}$. pylori spread solid agar plate (Fig. 3). It is also reported that the efficacy of crude leaf preparation having both non-active and active components is greater than semi crude drugs or pure plant substances (Kafaru, 1994). In a study conducted by Krishnan and Wong (2015), acetone and chloroform extract of neem leaf showed effective antimicrobial activity against various Gram-positive and Gramnegative bacteria. The results of an exploratory study showed that the potency of extracts was dependent on the concentration used. Therefore, an increase in the zone of inhibition is due to the increase in the concentration of the extract (Parashar et al., 2018). The leaves of $A$. indica possess significant antibacterial activity, which confirms the great potential of bioactive compounds.

This in turn is useful for rationalizing the use of $A$. indica in primary health care (Koona and Budida, 2011). While studying the anti-ulcer actity in HP-LPS (Helicobacter Pylori 26695 Lipopolysaccharide) induced rats, Kiranmai et al. (2014) had reported that the presence of flavonoids, tannins and other antioxidant principles in $A$. indica extracts may be responsible for mitigation of cellular damage and pathological changes caused by HP-LPS. It is shown that the leaf extract of $A$. indica (neem) had exhibited a powerful antibacterial activity against various strains of pathogenic bacteria (Hala, 2017). Raja Ratna Reddy (2013) reported higher antimicrobial activity in neem leaf extract compared to bark and seed. Authors have suggested variable distribution of phytochemical compounds in different parts for this difference. The elution of the TLC-scraped spots was done in order to find out the bioactive spots against $H$. pylori.

The results of elution and agar cup bioassay in the present study showed zone of inhibition of $11 \mathrm{~mm}$ against $H$. pylori (Fig. 4) supporting the antimicrobial activity. The Rf values were calculated for all the spots. The Rf values in the present study ranged from 0.15 to 0.88 . These values are indicative of larger less soluble pigments to highly soluble pigments suggesting the presence of phytochemicals of varied chemical nature. It is reported that presence of azadirachtin, quercetin and B-sitosterol 


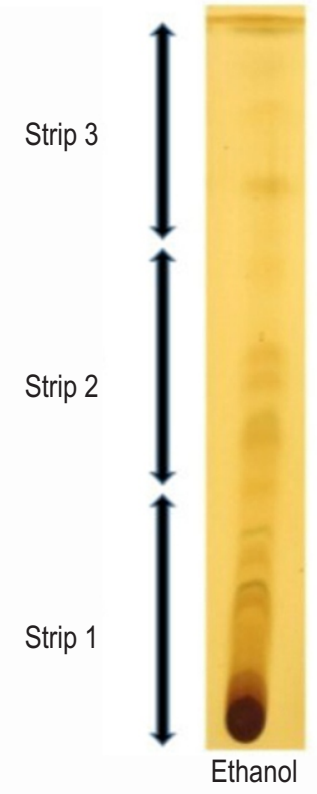

A

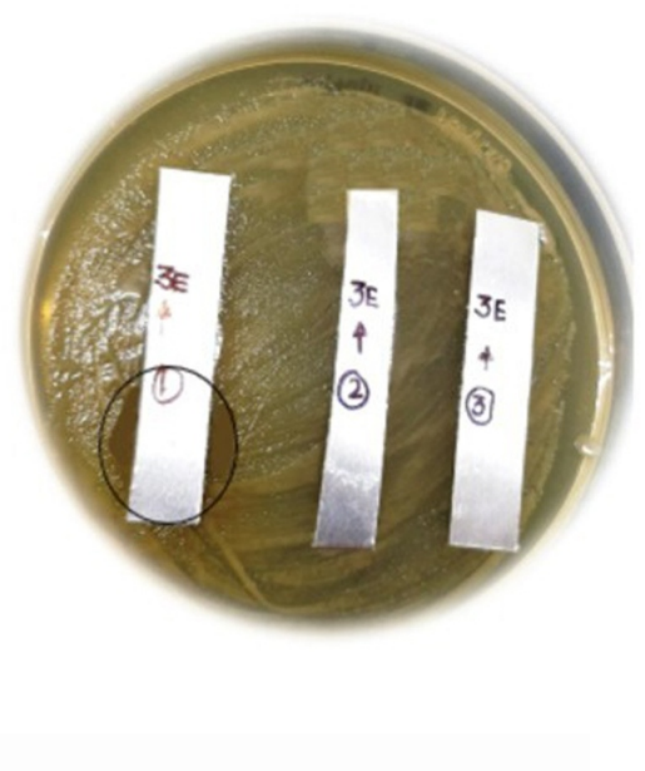

B

Fig. 3: (A) Thin layer chromatography strip of ethanolic extract of Neem (Azadirachta indica) leaf showing spots of bioactive compounds and (B) Contact Bioautography assay of strips 1,2 and 3 showing zone of Helicobacter pylorigrowth inhibition.

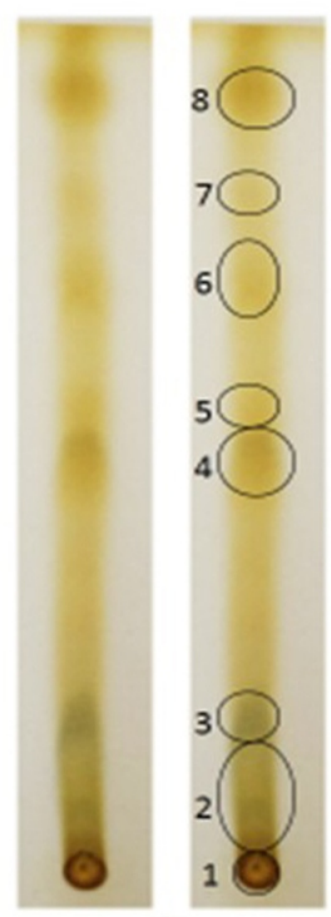

A

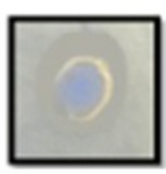

1

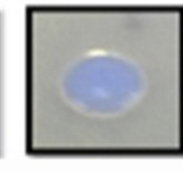

2

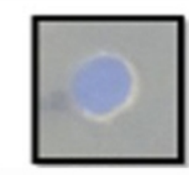

Silica

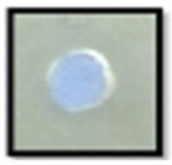

5

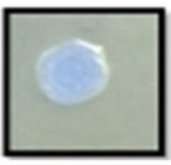

6

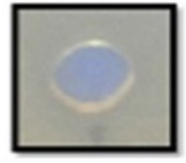

3

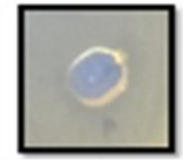

4

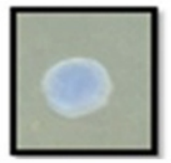

7

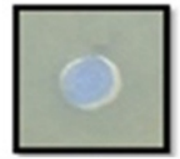

8

B

Fig. 4: (A) Manual Thin Layer Chromatography tiles prepared and loaded with ethanolic extract of Neem (Azadirachta indica) leaf showing bioactive spots and (B)Agar cup assay of scrapped bioactive spots showing zone of Helicobacter pylori growth inhibition. 
in neem ( $A$. indica) leaf might be responsible for strong antibacterial and antifungal activity compared to bark and seeds (Subapriya and Nagini, 2005). Thus, it can be concluded that the findings of the present study enabled in understanding the antibacterial potency of ethanolic extracts of neem (Azadirachta indica) leaf against Gram-negative gastric pathogen $H$. pylori. The ethanolic extract of neem leaf can be used as an effective natural remedy in combating or aiding the treatment of $H$. pylori infection.

\section{Acknowledgments}

The authors are thankful to the management of Amity University Uttar Pradesh for their constant support and encouragement. A sincere thanks to Dr. Sanjay Pathak of Narendra Dev University of Agriculture and Technology, Faizabad for providing the plant material. The work is part of Ph.D. programme of Ankita Saxena. We wish to express special thanks to fellow colleagues for their all-time cooperation.

\section{Add-on Information}

Authors' contribution: A. Saxena: Performed all the experiments, calculations and drafted the paper; $\mathbf{P}$. Arivaradarajan: Reviewed the technical and language part of the research article; A.K. Mukhopadhyay: Provided the Helicobacter pylori 26695 strain and has reviewed the manuscript; S.P. Nandi: Planned the experiments and has reviewed the manuscript both technically and grammatically.

Research content: The research content of manuscript is original and has not been published elsewhere.

Ethical approval: NotApplicable.

Conflict of interest: The authors declare that there is no conflict of interest.

Data from other sources: NotApplicable.

Consent to publish: All authors agree to publish the paper in Journal of Environmental Biology.

\section{References}

Al Akeel, R., A. Mateen, K. Janardhan and V.C. Gupta: Analysis of antibacterial and antioxidative activity of Azadirachta indica bark using various solvents extracts. Saudi J. Bio. Sci., 24, 11-14 (2017).

AI Saiqali, M., A.D. Tangutur, C. Banoth and B. Bhukya: Antimicrobial and anticancer potential of low molecular weight polypeptides extracted and characterized from leaves of Azadirachta indica. Int. J. Bio. Mac., 114, 906-921(2018).

Alzohairy, M.A.: Therapeutics role of Azadirachta indica (Neem) and their active constituents in diseases prevention and treatment. Evidence Based Compl. Alt. Med., Vol. 2016, 7382506 (2016).

Babayi, H., I. Kolo, J.I. Okogun and U.J.J. Ijah: The antimicrobial activities of methanolic extracts of Eucalyptus camaldulensis and Terminalia catappa against some pathogenic microorganisms
Biokemistri, 16, 106-111 (2004)

Blum, F.C., J. Singh and D.S. Merrell: In-vitro activity of neem (Azadirachta indica) oil extract against Helicobacter pylori. J. Ethnopharmacol., 232, 236-242 (2018).

Brown, L.M.: Helicobacter pylori: Epidemiology and routes of transmission. Epidemiol. Rev., 22, 283-297(2000).

Burkitt, M.D., C.A. Duckworth, J.M. Williams and D.M. Pritchard: Helicobacter pylori-induced gastric pathology: Insights from invivo and ex-vivo models. Dis. Models Mech., 10, 89-104 (2017).

Cellini, L, E.D. Campli, M. Masulli, S.D. Dartolomeo and N. Allocati: Inhibition of Helicobacter pylori by garlic extract (Allium sativum). FEMS Immunol. Med. Microbiol., 13, 277-279 (1996).

Dahiya, N., G. Chianese, O.T. Scafati, F. Esposito,G. Lupidi, M. Bramucci, L. Quassinti, G. Christophides, A. Habluetzel and L. Lucantoni: In-vitro and ex-vivo activity of an Azadirachta indica A. Juss seed kernel extract on early sporogonic development of Plasmodium in comparison with azadirachtin $\mathrm{A}$, its most abundant constituent. Phytomedicine, 23, 1743-1752 (2016).

Fabry, W., P. Okemo and R. Ansorg: Activity of eastAfrican medicinal plants against Helicobacterpylori. Chemotherapy, 42, 315-317 (1996a).

Fabry, W., P. Okemo and R. Ansorg: Fungistatic and fungicidal activity of eastAfrican medicinal plants. Mycoses, 39, 67-70 (1996b).

Fabry, W., P. Okemo and R. Ansorg: Antibacterial activity of East African medicinal plants. J. Ethnopharmacol., 60, 79-84 (1998).

Gupta, S.C., S. Prasad, A.K. Tyagi, A.B. Kunnumakkara and B.B. Aggarwal: Neem (Azadirachta indica): An Indian traditional panacea with modern molecular basis. Phytomedicine, 34, 14-20 (2017).

Graham, D.Y. and L. Fischbach: Helicobacter pylori treatment in the era of increasing antibiotic resistance. Gut, 59,1143-1153 (2010).

Hala A. Mohammed: Antibacterial activity of Azadirachta indica (Neem) leaf extract against bacterial pathogens in Sudan. Afr. J. Med. Sci., $2(2017)$.

Hooi, J.K.Y., W.Y. Lai, W. KhoonNg, M.M.Y. Suen, F.E. Underwood,D. Tanyingoh, P. Malfertheiner, D.Y. Graham, V.W.S. Wong, J.C.Y. Wu, F.K.L. Chan, J.J.Y. Sung, G.G. Kaplan and S.C. Ng: Global prevalence of Helicobacter pylori infection: Systematic review and meta-analysis. Gastroenterology, 153, 420-429 (2017).

International Agency for Research on Cancer: A review of human carcinogens. Part B: 579 Biological agents. International Agency for Research on Cancer, Lyons, France (2012)

Kafaru E.: Immense Help Formative Workshop. In.: Essential Pharmacology. $1^{\text {st }}$ Edn., Lagos, Nigeria, Elizabeth Kafaru Publishers. pp. 11-14 (1994).

Kiranmai, M., M. Ibrahim and C.B.M. Kumar: Evaluation of Azadirachta indica extracts against Helicobacter pylori 26695 lipopolysaccharide induced gastric ulcer in rats. Int. J. Indige. Medic. Plants, 47, 1723-1733 (2014)

Koona, S. and S. Budida: Antibacterial potential of the extracts of the leaves of Azadirachta indica Linn. Notul. Sci. Biologi., 3, 65 (2011). DOI: 10.15835/nsb.3.1.5470

Krishnan, Y. and N.K. Wong: Cytotoxicity and antimicrobial properties of neem (Azadirachta indica) leaf extracts. Int. J. Pharm. Pharm. Sci., 7, 179-182 (2015).

Kumar, S., K. Jyotirmayee and M. Sarangi: Thin layer chromatography: A tool of biotechnology for isolation of bioactive compounds from medicinal plants. Int. J. Pharm. Sci. Rev. Res., 18, 126-132 (2013).

Malekzadeh, F., H. Ehsanifar, M. Saharnat, M. Levin and R.R. Colwell: Antibacterial activity of Blachmyrobalam (Terminalia chebula Retz) against Helicobacter pylori. Int. J. Antimicrob. Ag., 18, 85-88 (2001)

Mehrotra, S., A.K. Srivastava and S.P. Nandi: Comparative antimicrobial activities of neem, amla, aloe, assam tea and clove extracts 
against Vibrio cholerae, Staphylococcus aureus and Pseudomonas aeruginosa. J. Med. Plants Res., 4, 2393-2398 (2010).

Moghaddam, M.N.: In-vitro inhibition of Helicobacter pylori by some spices and medicinal plants used in Iran. Global J. Pharmacol., 5, 176-180 (2011).

Nadkarni A. K.: Nadkarni's Indian Materia Medica. $3^{\text {rd }}$ Edn., Popular Book Depot, Bombay (1954).

Newman, D.J. and G.M. Cragg: Natural products as sources of new drugs from 1981 to 2014. J. Nat. Prod., 79, 629-661(2016).

National Research Council: DNA Technology in Forensic Science. Washington, DC. The National Academies Press (1992). https://doi.org/10.17226/1866

Parashar, G., N. Sutar and S. Sanap: Antibacterial activity of mixture of leaf extracts of Neem (Azadirachta indica linn.) and Tantani (Lantana camara). Int. J. Pharm. Sci. Res., 9, 2545-2549 (2018).

Parida, M.M., C. Upadhyay, G. Pandya and A.M. Jana: Inhibitory potential of neem (Azadirachta indica Juss) leaves on Dengue virus type-2 replication. J. Ethnopharm., 79, 273-278 (2002).

Perez, C., M. Paul and P. Bazerque: An Antibiotic assay by the agar well diffusion method. Acta. Bio. Med. Exp., 15, 113-115 (1990).

Raja Ratna Reddy, Y., C. Krishnakumari, O. Lokanatha, S. Mamatha and C. Damodar Reddy: Antimicrobial activity of Azadiractha indica (neem) leaf, bark and seed extracts. Int. J. Res. Phytochem. Pharmacol., 3, 1-4 (2013)
Saxena, A., A.K. Mukhopadhyay and S.P. Nandi: Helicobacter pylori: Perturbation and restoration of gut microbiome. J. Biosci., 45, 110 (2020a).

Saxena, A., A.K. Mukhpadhyay and S.P. Nandi: Antibacterial activity of selected plants extract against pathogenic bacteria and detection of phytochemicals. J. Environ. Biol., 41, 1486-1492 (2020b).

Saradhajyothi, K. and B. Subbarao: Antibacterial potential of the extracts of the leaves of Azadirachta indica Linn. Notu. Sci. Biologicae, 3, 65-69 (2011)

Stefano, K., M. Marco, G. Federica, B. Laura, B. Barbara, L. Gioacchino di M. Francesco and L. de'A. Gian: Helicobacter pylori, transmission routes and recurrence of infection: State of the art. Acta Biomed., 89, 72-76 (2018).

Subapriya, R. and S. Nagini: Medicinal properties of neem leaves: A review. Curr. Med. Chem. AnticancerAgen., 5, 149-6 (2005).

Thakurta, P., P. Bhowmik, S. Mukherjee,T.K. Hajra, A. Patra and P.K. Bag: Antibacterial, antisecretory and antihemorrhagic activity of Azadirachta indica used to treat cholera and diarrhea in India. $\mathrm{J}$. Ethnopharm., 111, 607-612(2007).

Thung, I., H. Aramin, V. Vavinskaya, S. Gupta, J.Y. Park, S.E. Crowe and M.A. Valasek: Review article: the global emergence of Helicobacter pyloriantibiotic resistance. Ali. Pharm. Ther., 43, 515-533 (2016).

Warren, J.R. and B.J. Marshall: Unidentified curved bacilli on gastric epithelium in active chronic gastritis. Lancet, 1, 1273-1275 (1983). 